\title{
Light as a reinforcer of pecking in tube-fed leghorn chicks'
}

GRAHAM M. STERRITT

UNIVERSITY OF COLORADO MEDICAL CENTER

Chicks maintained in dim light developed high peck rates for $10 \mathrm{sec}$. of bright light on a CRF schedule. Controls given $10 \mathrm{sec}$. of bright light arbitrarily every $15 \mathrm{~min}$. pecked reliably less.

The goal of the present study was to determine whether leghorn chicks in dim light would learn to peck at a key that delivered increased illumination. It is well known that moderate increases in illumination are reinforcing to the rat (Lockard \& Lockard, 1964). However, the rat is a nocturnal species known to be photophobic to brighter light (Keller, 1941). In contrast, chickens are active in the light and rest in the dark portion of the day-night cycle (Wood-Gush, 1959), to this extent at least, showing phototrophic tendencies. Thus, the chicken might be a more appropriate species for use in further research on this problem.

Method

Ss were $24 \mathrm{Hy}$-line No. 934 cockerels obtained from a commercial source. Since chicks raised in dim light often starve (Shreck et al, 1963), it appeared desirable to maintain Ss by tube feeding. Therefore, about $12 \mathrm{hr}$. after hatching a plastic fistula was implanted, under anesthesia, in the esophagus of each S. Beginning at about $36 \mathrm{hr}$. after hatching, a mixture of food and water was injected into the esophagus of each S every $15 \mathrm{~min}$., $24 \mathrm{hr}$./day, via a spiral of plastic tubing attached to the esophageal tube. The external tube was left attached and the chicks were tube-fed without opening the cubicles. Details of the surgery and diet are given elsewhere (Sterritt \& Smith, 1965).

The chicks were hatched as a group, then operated and placed in individual cubicles maintained at $35^{\circ} \mathrm{C}$. Each cubicle was illuminated by a 10-W frosted lamp $32 \mathrm{~cm}$ above the floor until $36 \mathrm{hr}$. after hatching, after which this lamp was off, except as noted below.

A panel introduced at $36 \mathrm{hr}$. post-hatch contained a translucent white key $25 \mathrm{~mm}$ in diameter, $11 \mathrm{~cm}$ above the floor, which transmitted light from a No.110 Drake neon lamp. This dim light was the only source of illumination except for the reward light. Three plastic beads were attached to the key to enhance its attractiveness as a peck target. The key operated a BZ-RW 8435 Microswitch connected to a magnetic counter, operation of which was audible to the chick.

In the LR (light reward) group $(\mathrm{N}=12)$ a peck at the key delivered $10 \mathrm{sec}$. of light from the 10-W frosted lamp. The NR (no reward) group $(\mathrm{N}=12$ ) did not receive the light after pecking, but instead received $10 \mathrm{sec}$ of light every $15 \mathrm{~min}$. automatically, 5-10 $\mathrm{min}$. from the last tube-feeding.
When an $\mathrm{S}$ in either group pecked fewer than three times in an $8 \mathrm{hr}$. period, it was guided to the key 5-10 min. from the time of tube-feeding and two pecks were gently elicited. This procedure was repeated $10 \mathrm{sec}$. later until a total of 10 pecks had been elicited, unless $\mathrm{S}$ spontaneously completed the balance of 10 pecks.

Twelve unoperated Ss, given food and water ad lib, were maintained in groups of three in well-lighted cubicles to provide body weight norms. The schedule of tube-feeding was such that the tube-fed groups were maintained above the unoperated controls in body weight (mean body weight gain: LR group, 29.14; NR group, 30.03; unoperated controls, 25.62; tube-fed Ss vs unoperated Ss, $t=2.155, d f=34, p<.025)$.

Results

An analysis of variance was carried out with the two groups and five days as independent variables and pecks per $24 \mathrm{hr}$, as the dependent variable. In Fig. 1 it can be seen that the NR group delivered large numbers of pecks to the target, averaging about 500 pecks per day on days 2-5. The maximum rate for a single $S$ in this group was 3,000 recorded pecks in one $8 \mathrm{hr}$. period. Nonetheless, the LR group pecked reliably more $(F=10.029, \mathrm{df}=1 / 22, \mathrm{p}<.01)$. There was a significant increase in peck rates in both groups as a function of days $(F=3.017, d f=4 / 88, p<.05)$, though this effect appears mainly over the first one or two days. Thereafter both groups appeared to show stable rates of pecking. The interaction between groups and days was not significant.

The numbers of chicks that had to be forced to peck offer an index to the lower end of the peck-score distribution. In the NR group, three chicks had to be forced, even on day 5 . In the LR group, no forcing was required after the first $8 \mathrm{hr}$. of day 2 .

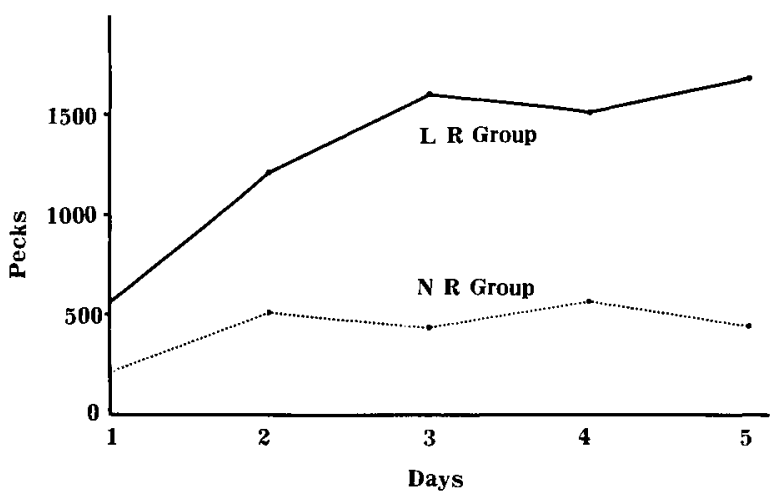

Fig. 1. Mean number of pecks on days 1-5. 
Ordinarily, chicks deliver pecks in "bursts" within which the rate is better than one peck/sec. The NR group exhibited this pattern of peck behavior. In contrast, the LR Ss almost invariably pecked just once, turning on the light. They rarely pecked while the light was on, but the termination of the light was often followed immediately by another single peck, reinstating the light.

When the data of the LR group was examined by $8 \mathrm{hr}$. intervals, a spontaneous circadian cycle of pecking was found, with greater numbers of pecks from midnight to 8 A.M., fewer from 8 A.M. to 4 P.M. and least from 4 P.M. until midnight. When peck scores were summed across days 3,4 , and 5 within each of the three $8 \mathrm{hr}$. periods, it was found that the mean peck score for the midnight to 8 A.M. period, 803 pecks, reliably exceeded the mean of 361 pecks delivered from 4 P.M. to midnight ( $t$ for paired observations $=2.674$, $d f=11, p<.05$ ). The mean for 8 A.M. to 4 P.M., 450 pecks, did not differ reliably from either of the other means. No comparable trend was apparent in the data of the NR group, suggesting that the rhythm of pecking in the LR group may have served the function of creating a day-night cycle of light.

\section{Discussion}

The findings of this study indicate that the delivery of a moderate increase in illumination is a reliable reinforcer of pecking in the leghorn chick maintained in near-darkness. The high rates of pecking sustained by most chicks in the NR group suggest that a dimly lighted target is a sufficient extroceptive incentive for pecking in many Ss, though this stimulus is clearly a more reliable incentive when coupled with light rewards.

Ss were tube-fed very frequently, in amounts sufficient to cause them to grow at a greater than normal rate. The tube-fed Ss should, therefore, have experienced little, if any, hunger or thirst. None of the Ss ever consumed food or water by mouth. Thus, hunger and thirst needs and consummatory habits are obviously not pre-requisite to the development of high rates of pecking for extroceptive incentives.

It is interesting to note that canaries permitted to control environmental illumination generally put themselves on a rhythm such that one period of light and one of darkness occur approximately every $24 \mathrm{hr}$. (Wahlstrom, 1964). The findings of the present study point to the possibility that leghorn chicks having minimal experience with diurnal dark-light cycles may do the same.

\section{References}

Keller, F. S. Light-aversion in the white rat. Psychol. Rec., 1941, 4, 235-250.

Lockard, R. B., \& Lockard, J. S. Stimulus-change versus preference for light. Psychol. Rep., 1964, 15, 191-198.

Wood-Gush, D. G. M. Time-lapse photography: A technique for studying diurnal rhythms. Physiol. Zoo., 1959, 32, 272-283.

Shreck, P. K., Sterritt, G. M., Smith, M. P., \& Stilson, D. W. Environmental factors in the development of eating in chicks. Anim. Behav., 1963, 11, 306-309.

Sterritt, G. M., \& Smith, M. P. Feeding chicks exclusively via implanted plastic fistulas. Psychon. Sci., 1965, 2, 177-178.

Wahlstrom, Goran. The circadian thythm in the canary studied by self-selection of light and darkness. Acta soc. med. Upsal., 1964, 69, 241-271.

\section{Note}

1. This research was supported by a grant (HD 00334) from the National Institute of Child Health and Human Development. The author is the recipient of a Research Career Development Award from the same Institute. 